doi 10.7213/comunicao.35.014AO02 e-ISSN 1982-8675 Licenciado sob uma Licença Creative Commons

\title{
Webcasting como jornalismo de internet: uma análise da pragmática da comunicação digital
}

\author{
Webcasting as internet \\ journalism: a pragmatic analysis \\ of digital communication
}

Rafael Duarte Oliveira Venancio

\section{Resumo}

0 presente trabalho pretende analisar o webcasting como prática representante do chamado Jornalismo de Internet. Utilizando um arcabouço teórico da filosofia analítica da linguagem, com destaque para a pragmática de John R. Searle, o objetivo é mostrar como o webcasting ajuda o jornalismo encontrar uma linguagem e lógica próprias dentro do campo das mídias digitais. O foco metodológico é na aplicação da taxonomia das doze diferenças que compõe a força ilocucionária, resultando assim em uma separação, a nível pragmático, da ação linguística do Jornalismo de Internet perante os demais.

Jornalista, doutor em Meios e

Processos Audiovisuais pela Escola de Comunicações e Artes da Universidade de São Paulo (USP), professor do curso de Jornalismo da Universidade Federal de Uberlândia (UFU), Uberlândia, MGBrasil, e-mail: rdovenancio@gmail.com

Palavras-chave: Jornalismo.

Linguagem midiática. Webcasting. Internet. 


\begin{abstract}
This paper analyzes webcasting as a representative practice inside Internet Journalism. Using a theoretical framework of analytic philosophy of language, with emphasis on John R. Searle's pragmatics, the objective is to show how webcasting helps journalism to find a language and a logic of its own within the field of digital media. The methodological focus is on the application of the taxonomy of the twelve differences that composes the illocutionary force, resulting in a separation, in a pragmatic level, of the linguistic action of Journalism Internet towards the other.
\end{abstract}

Keywords: Journalism. Media language. Webcasting. Internet.

Há um desafio intrínseco a qualquer texto que pretenda trabalhar algum aspecto daquilo que chamamos de mídias digitais: lidar tanto com a eterna construção teórica e epistemológica quanto com as constantes mutações que a prática digital sofre ao longo do tempo. Aliás, a própria questão da nomenclatura desse tipo de jornalismo merece um debate em separado.

Afinal, o nome mais amplo de produção jornalística em mídias digitais não possui a tradição que normalmente nomeia as práticas do jornalismo. Se usamos o rádio para fazer jornalismo, falamos em radiojornalismo. Televisão, telejornalismo. Fotografia, fotojornalismo. E no caso do jornalismo em mídias digitais?

Ao longo do tempo, surgiram alguns nomes adotados por alguns teóricos, tais como jornalismo multimídia, jornalismo online, jornalismo digital, ciberjornalismo. No entanto, cada um dele usa um foco histórico para definir tal função.

O jornalismo multimídia foi aquele que surgiu antes, com a ideia de um jornalismo multidisciplinar calcado na figura do repórter. O jornalista multimídia seria aquilo que chamamos de um jornalista-orquestra. Ele vai até o fato para escrever (com um notebook), tirar fotos (com uma câmera digital), gravar depoimentos em vídeo ou apenas em áudio com um aparato digital apropriado, edita sua matéria e a posta no ar, onde monitora sua visualização.

Com isso, o jornalista multimídia se torna apenas a definição do trabalho do jornalista na era digital. A exigência de um trabalhador que é amálgama de repórter, repórter fotográfico/audiovisual e editor. No 
entanto, não abarca mais todo o fenômeno, porque, até para veículos impressos ou audiovisuais, ser multimídia é uma necessidade. Basta pensar que muito do telejornalismo praticado hoje em dia, com o advento do aparato audiovisual digital, tais como programas de edição não linear e câmeras que registram diretamente em arquivos digitais, exige-se um repórter multimídia para veicular no sistema tradicional de broadcast que, por ter um sinal codificado na atual tecnologia, chama-se televisão digital, mas que existe autonomamente daquilo que chamamos de web, ou seja, a World Wide Web (WWW).

Já o jornalismo online está preocupado com a veiculação do jornalismo na web. Aqui, não está posta apenas a questão da produção de novos conteúdos, mas também a transposição dos conteúdos tradicionais para colocá-los online. Com isso, o mundo web se torna muito mais uma caixa de publicização e de redundância dos meios tradicionais do que uma atividade autônoma dentro do jornalismo.

Assim, há o chamado jornalismo digital, que estaria calcado em tudo aquilo que foi criado, como produtos jornalísticos, diretamente na web. No entanto, falta ao nome uma força epistemológica. Na era digital, tudo é digital, inclusive o broadcast e os demais meios tradicionais. Falamos inclusive sobre cinema digital, mas continuamos a vê-lo em uma sala de exibição tal como nos tempos dos Irmãos Lumière, tendo apenas a opção de vê-los online, tal como temos a opção de vê-los em casa em uma televisão.

O uso alternativo da nomenclatura ciberjornalismo também possui seus problemas. Normalmente utilizado para definir uma atitude do jornalista diante das mídias digitais - afinal, o jornalista do século XXI entra em contato com as fontes por email, possui redes sociais tais como Facebook e Twitter, escreve um blog, dentre outras coisas -, o prefixo ciber possui a mesma falha epistemológica da complementação digital.

Afinal, tudo é ciber na atualidade porque nós estamos em pleno contato com as máquinas digitais. Basta pensar que para as palavras de um livro, por exemplo, chegarem à sua apreciação via leitura, elas precisaram ser digitadas pelo autor em um processador de texto digital em um notebook, gerando um arquivo digital que foi enviado por email para a apreciação da editora. Após aprovado, a editora utilizou outros softwares para diagramá-lo e enviou por protocolos digitais para a impressão, chegando até você (com ajuda de outros processos mediados pela era digital, tal como distribuição e comercialização) no bom e velho formato do livro impresso. Hoje em dia, até o nosso papel é ciber. 
Com isso, o nome que se torna o mais utilizado atualmente é o webjornalismo, ou seja, o jornalismo que se utiliza da World Wide Web enquanto meio de produção e de veiculação. Por uma questão epistemológica, utilizar o termo web parece restrito demais: a web é apenas uma das maneiras que as pessoas podem ser conectar, calcadas nos protocolos de hiperlinks (HTTP). Pensando nas inúmeras possibilidades futuras de conexão entre as pessoas, o interessante não é utilizar a comum metonímia que toma a parte (a web) pelo todo (a internet).

Dessa forma, ao invés de webjornalismo, há aqui uma preferência pelo termo jornalismo de internet. Podemos elencar duas amplas razões pela adoção desse nome para designar tanto a teoria como a prática envolvendo as plataformas jornalísticas nas mídias digitais. São elas: (1) a questão da necessidade de não confundir internet com World Wide Web, bem como seus potenciais; e (2) a colocação do termo jornalismo em maior proeminência.

A questão da confusão feita entre internet e web em si é um amplo debate na comunidade digital. Muitas vezes, enquanto falamos e lemos algo sobre internet, estamos apenas falando sobre a web. Esse típico erro de um usuário pouco familiarizado com a tecnologia digital gerou, inclusive, um neologismo: interwebs. Sob a forma de memes, essa expressão normalmente serve para designar a confusão metonímica que é feita achando que o mundo dos hiperlinks é a internet.

Há aqui uma necessidade de uma breve recapitulação teórica e histórica. A internet, nada mais nada menos, é uma rede de backbones (ou seja, a conexão entre computadores, seja servidores ou clientes) comercializada a partir do começo dos anos 1990. Um dos serviços que a internet presta é a conexão, via browser, para a World Wide Web. Idealizada por Tim Berners-Lee entre 1989-90, o WWW é uma rede de documentos hiperlinkados entre si, sendo que esses documentos podem conter desde páginas do formato próprio da web (HTML, PHP), até arquivos digitais de texto, imagem, vídeo e som.

Assim, tudo que é feito no WWW é feito na internet, mas essa não é a única forma de utilizar a amplitude internética, inclusive de maneira jornalística. Para utilizar um exemplo vivaz no nosso cotidiano, podemos citar aqui as redes P2P (peer-to-peer) que são uma opção - muitas vezes, libertária - de compartilhamento de arquivos digitais. Por isso que quando falamos de mídias digitais, a web não é o limite: seu verdadeiro suporte é a internet.

Já a segunda razão é bastante clara: a valorização do termo jornalismo. Isso é um debate que podemos fazer em ampla escala: fotojornalismo ou 
jornalismo fotográfico, telejornalismo ou jornalismo televisivo, radiojornalismo ou jornalismo radiofônico? Ora, o jornalismo possui um diferencial em relação ao amplo espectro dos meios de comunicação: ele é uma atividade humana que, muito rapidamente, adaptou-se a múltiplos suportes.

Com o advento da reprodutibilidade técnica do som e da imagem, o jornalismo e, até mesmo, a ideia de jornal se libertaram da questão impressa. Aliás, até mesmo no impresso, torna-se possível pensar em múltiplos suportes, tais como revistas, boletins murais e livros. Isso se coloca porque o jornalismo é uma práxis comunicacional que não necessita de suporte para existir, ao contrário de outras práticas midiáticas tais como as atividades específicas da fotografia, do rádio, do cinema, da televisão e, até mesmo, da internet (tal como as redes sociais). Aliás, o jornalismo se utiliza dessas atividades específicas, via sua deontologia, para se realizar.

Por isso que o termo jornalismo de internet, aqui adotado, parece-nos mais correto. Não estamos falando apenas daquilo que é um jornalismo posto na internet, mas sim o que a internet pode oferecer, como suporte, ao jornalismo. Os valores jornalísticos, grosso modo, mantém-se os mesmos, mudam-se apenas as possibilidades.

Abarcando esse mundo de possibilidades, o presente artigo busca entender o webcasting como prática ideal do jornalismo de internet. Cada vez mais, em contraposição ao modelo tradicional de broadcast, está sendo desenvolvida na internet uma série de alternativas a esse modelo, proporcionando não só a mudança na relação jornalista-público, mas também nos processos de periodicidade da notícia e de seus valores ordenadores. Assim, além de caracterizar o que é webcasting, o artigo estudará como essa prática representa bem a pragmática, a ação linguística, do jornalismo de internet.

O arcabouço teórico para tal análise será a filosofia analítica da linguagem, com enfoque na pragmática. Com isso, utilizaremos a ideia das diferenças da lógica ilocucionária, de John R. Searle, para caracterizar as distinções e desafios linguísticos postos por essa prática midiática.

\section{A ideia de webcasting}

Um dos caminhos futuros para a World Wide Web como suporte comunicacional está a questão da adaptação do universo broadcast a seu meio. $\mathrm{O}$ que temos aqui, na questão jornalística, é sua adaptação de 
universo audiovisual dedicado a aparelhos de origem "analógica" (rádio, TV) para o mundo digital hipermidiático.

No entanto, o universo audiovisual possui uma concepção mcluhaniana de que a sociedade é moldada pela tecnologia. As pessoas assistem à TV da maneira como é pautada a elas. Esse paradigma é quebrado inicialmente, especialmente nas questões audiovisuais, com o advento dos estudos culturais, e consolidado quando temos a evolução da internet. Aqui, em um mundo de prosumers e ampla construção de leitores-modelo, vemos uma domesticação dos meios pela sociedade e não o contrário.

A teoria da domesticação, que descreve o processo de adaptação por parte dos usuários a suas necessidades específicas, nos permite compreender em um sentido pragmático o passo da web 1.0 para a web 2.0. Tal teoria, formulada inicialmente por Roger Silverstone para explicar a adoção e o uso das novas TIC no lar, reflete a recíproca e constante influência entre a tecnologia e a cultura, que foi capaz de configurar a Internet como um grande fórum público em escala mundial. A teoria da domesticação evidencia o papel ativo do usuário no pleno desenvolvimento do potencial tecnológico de cada nova aplicação e, em sua aliança com a televisão, converte o espectador ativo (o leitor-modelo de Eco redescoberto pelos Estudos Culturais nos anos 1980) em produtor (LACALLE, 2010, p. 86).

Com a facilidade posta pela web e pelo barateamento do dispositivo de produção audiovisual, a tendência para internet é termos, tal como colocam autores como Newcomb e Hirsch, realizadores hipermidiáticos que agem como bricoleurs culturais. Aqui, a comunicação é vista

como um processo de reconstrução e de renegociação da realidade e consideram os produtores como bricoleurs culturais. Uma qualidade que os citados autores também atribuem ao espectador, ao homologar sua projeção nos textos ou sua identificação com os personagens televisivos com a aspiração de muitos produtores de introduzir em seus programas ideias próprias ou de utilizar a televisão como um meio de expressão pessoal (LACALLE, 2010, p. 86).

Para esses bricoleurs, o ciberespaço é o ambiente ideal para tais construções. Isso torna a internet um ambiente ideal para uma reconfiguração do broadcasting, resignificado enquanto webcasting. 
O conceito de bricoleur cultural de Newcomb e Hirsch parece-nos útil para definir, na atualidade, a crescente atividade de um espectador transformado em usuário, que se multiplica na Rede e introduz na interpretação retalhos de sua realidade cotidiana, inclusive de sua própria biografia. Um espectador transformado em uma constante fonte de inspiração para os responsáveis das diferentes produções, cujo feedback através da Internet (chat, fóruns, blogs, redes sociais etc.) configura uma viagem circular, de ida e volta desde a produção até a recepção, que engloba o paratexto (Genette) no texto, e a construção de significação na produção dos programas (LACALLE, 2010, p. 86-87).

O jornalismo de internet precisa lidar com esse universo digital, no qual os relatos em "tempo real", cujo mecanismo de ponta são os webcasts audiovisuais, podem ser feitos por todos. Tal como

De qualquer modo, a agenda noticiosa não é mais a única maneira de dar conta da realidade e já não são mais atribuídas apenas às notícias a credibilidade e a influencia social exercida pelas informações. Agora os gêneros discursivos estão cada vez mais misturados, os textos podem ser híbridos e transmitidos por diferentes suportes. Desse modo, o vínculo exclusivo dos relatos jornalísticos com a tradução da realidade é desafiado, ou seja a compreensão do jornalismo como lugar exclusivo de referência da realidade. Parece que as pessoas já não têm mesmo necessidade da imprensa como antes, porque estão disponíveis muitos outros canais de informação. Mas, precisam de uma informação profissional e confiável sobre os acontecimentos que merecem ser conhecidos quando ajudam a compreender e a melhorar a sociedade na qual vivemos (BECKER; MATEUS, 2011, p. 3-4).

Com isso, começam a surgir iniciativas de produção noticiosa para ajudar o jornalista a realizar esse papel de mediador, curador e ativista que necessita no campo da Internet. Além dos tradicionais meios de podcasting - entendido aqui enquanto a disponibilização de arquivos de áudio (podcasts sonoros, audiocasts, postos em plataformas dedicadas - iTunes, Pod-o-matic - ou em sites, portais e blogs) e/ou vídeo (videocasts, normalmente postos em canais do YouTube/Vimeo ou "embedados" em outras páginas) sem o compromisso da transmissão em tempo real - o webcasting, entendido aqui enquanto o streaming 
audiovisual em tempo real, se configura para buscar a transposição midiática necessária entre meios tradicionais e digitais.

Surgem assim as webrádios e webtevês, bem como as ciberrádios e cibertevês. As primeiras, segundo o caráter usual da nomenclatura, são apenas a transmissão web de um sinal que existe para outros meios (ex: o simulcast da Globo na TV e na web). Já as segundas, com o seu prefixo ciber, existem apenas na internet.

O embate entre os webaudiovisuais e os ciberaudiovisuais possibilita a expansão do mercado jornalístico na internet. Afinal, enquanto os webs atingem os hits de popularidade, pegando o fluxo tradicional de financiamento publicitário inclusive, os cibers ficam com o mercado de nicho, aproveitando o mecanismo da cauda longa, tal como descrito por Chris Anderson. No entanto, por não terem outro mercado publicitário consolidado para se calcar, as cibers precisam lutar por novos modelos de financiamento.

Já a luta dos webaudiovisuais está na quebra do broadcasting tradicional, visando à maior interatividade e aproximação do público da internet, sempre identificado como um prosumers. Podemos, inclusive, elencar três fases dessa estratégia de inserção hipermidiática:

Classificaríamos, portanto, como de primeira fase, aquelas que somente transferem o mesmo conteúdo audiovisual exibido em rede aberta de televisão para bancos de dados da internet. A medida, além de atribuir um caráter mais moderno a imagem da empresa de comunicação no contexto local, serve também como alternativa para o telespectador que não pôde se ajustar a rigidez dos horários da grade de programação da TV. Na segunda etapa dessa evolução, estariam as emissoras que já produzem um conteúdo exclusivo para a web, mas usam a internet apenas como um suporte para a transmissão - ao vivo ou não - dos programas, que são produzidos ainda de acordo com a lógica da TV convencional. Ou seja, sem explorar "as potencialidades oferecidas pela Internet ao jornalismo desenvolvido para a web". As emissoras pertencentes à terceira fase, além de produzirem conteúdos exclusivos para a internet e de procurarem explorar os recursos de convergência, interatividade, hipertextualidade e memória também oferecem a opção de personalização no que se refere à ordem de exibição dos conteúdos (NOGUEIRA, 2004, p. 3).

Uma das saídas para essa terceira fase é a chamada "segunda tela". Essa segunda tela, nada mais nada menos, é uma janela associada ao streaming ou um tablet/notebook associado à televisão. Nessa segunda 
tela, o público teria informações adicionais acerca da notícia ou mesmo outros materiais de repercussão, aprofundando sua participação, experiência e compreensão do fato noticioso.

Além disso, o embate audiovisual entre webs e cibers possibilita o desenvolvimento de material independente, dando voz para pautas antes esquecidas, e aproximando o uso do telejornalismo e do radiojornalismo de grupos sociais sem acesso à sua produção. $\mathrm{O}$ webcasting, sem dúvida, é um forte mecanismo para um ativismo jornalístico e para a democratização do acesso à Comunicação Social.

\section{Pragmática do webcasting}

Dentro desse quadro, há a necessidade de verificar como se dá a ação jornalística digital, ponto de mescla entre essas duas pragmáticas, constituindo um uso perfomativo ilocucionário específico. Para isso, precisamos caracterizar tal pragmática pelas 12 dimensões ilocucionárias derivadas da taxonomia de Searle. Para entendê-las, precisamos retornar ao ponto central da pragmática, do estudo da ação da linguagem: os atos de fala teorizados por J. L. Austin.

"O ponto de partida da teoria clássica dos atos de fala é a seguinte convicção: a unidade mínima da comunicação humana não é nem a frase nem qualquer outra expressão. É a realização (performance) de alguns tipos de ato" (ARMENGAUD, 2006, p. 99). No entanto, qual é a base dessas performances linguísticas? Quais são os parâmetros desse tipo de ação na linguagem?

Assim, "a teoria dos atos de fala é um estudo sistemático da relação entre os signos e seus intérpretes. Trata-se de saber o que fazem os intérpretes-usuários, que atos eles realizam pelo uso de certos signos" (ARMENGAUD, 2006, p. 100). Austin divide em três grandes grupos de atos de fala: locucionários, ilocucionários e perlocucionários.

Quantos sentidos podem haver onde dizer algo é fazer algo, ou no dizer algo fazemos algo, ou mesmo por dizer algo fazemos algo. Nós, primeiro, distinguimos um grupo de coisas que nós fazemos ao dizer alguma coisa, que ao dizê-las nós realizamos um ato locucionário, que é, grosso modo, equivalente ao enunciar certa sentença com um determinado sentido e referência, que novamente é equivalente, grosso modo, a "significar" no sentido tradicional. Segundo, nós dissemos que também realizamos atos ilocucionários tais como informar, ordenar, empreender, etc., i.e. 
enunciados que possuem uma certa (convencional) força. Terceiro, nós podemos também realizar atos perlocucionários: aquilo que nos traz ou conseguimos por dizer alguma coisa, tal como convencer, persuadir, dissuadir, e até mesmo, surprender ou enganar. Aqui nós temos três, ou mesmo mais, sentidos ou dimensões diferentes do "uso de uma sentença" ou do "uso de uma linguagem" (e, claro, há outras também) (AUSTIN, 1975, p. 109-110).

No entanto, é errôneo achar que as sentenças performativas se limitam a esses verbos tradicionais que Austin passa boa parte de sua magnus opus analisando. Ora,

Austin argumenta que uma sentença como "O gato está sobre o capacho" que tem sido analisada como declarativa [...] e, portanto, passível de ser considerada verdadeira ou falsa, é de fato uma sentença "performativa", que não pode ser considerada verdadeira ou falsa, mas apenas feliz ou outra coisa qualquer, dependendo das circunstâncias em que foi proferida (RAJAGOPALAN, 2010, p. 26).

Com isso, Austin desenha a ideia de uma força performativa dentro da linguagem. Força essa que estaria no cerne de qualquer linguagem em plena articulação com as proposições que a compõe. No entanto, se Austin constatou tal força juntamente com o protagonismo dos atos de fala em uma concepção pragmática da linguagem, foi Searle que, de fato, cumpriu a ideia - implícita no pensamento austiniano - de sistematização desses performativos, tanto da sua força como de seus atos.

Em Speech Acts, Searle define a força performativa (ou força ilocucionária) nos moldes de uma função, $F(p)$, "onde a variável $F$ está para a força ilocucionária indicando dispositivos enquanto valores e $p$ está para expressões para proposições" (SEARLE, 1976, p. 31). Assim, além de corroborar na participação da força ilocucionária enquanto parte do significado (SEARLE; VANDERVEKEN, 2009, p. 7), ele indica que, na fórmula $F(p)$, reside a ideia de uma lógica ilocucionária que poderia ser a base de uma gramática universal, tal como no sentido posto por Montague (1970).

Sendo que forças ilocucionárias e proposições são os dois componentes do significado das sentenças elementares, a linguagem ideal da gramática universal deve conter constantes lógicas e operadores capazes de gerar nomes para todas as forças ilocucionárias possíveis de enunciados. Qualquer sentença em qualquer linguagem natural deve ser traduzida 
em sentenças da linguagem ideal da gramática universal e essas sentenças devem refletir a potencialidade ilocucionária das sentenças da língua natural. Até o presente momento, a gramática universal se preocupou mais com as proposições, mas também necessita incluir um relato das forças ilocucionárias (SEARLE; VANDERVEKEN, 2009, p. 8).

Para verificar a força ilocucionária, Searle constrói uma taxonomia própria baseada nas 12 diferenças que tornam possível a classificação dos diferentes tipos de $F$ em $F(p)$ (SEARLE, 2002, p. 2-11). São elas:

1) Diferenças quanto ao propósito do (tipo de) ato.

2) Diferenças quanto à direção do ajuste entre as palavras e o mundo.

3) Diferenças quanto aos estados psicológicos expressos.

4) Diferenças quanto à força ou ao vigor com que o propósito ilocucionário é apresentado.

5) Diferenças quanto ao estatuto ou à posição do falante e do ouvinte, no que isso concerne à força ilocucionária da emissão.

6) Diferenças quanto ao modo como a emissão se relaciona com os interesses do falante e do ouvinte.

7) Diferenças quanto às relações com o resto do discurso.

8) Diferenças quanto ao conteúdo proposicional determinadas pelos dispositivos indicadores da força ilocucionária.

9) Diferenças entre os atos que devem sempre ser atos de fala e os que podem, mas não precisam, ser realizados como atos de fala.

10) Diferenças entre os atos que requerem e os que não requerem instituições extralinguísticas para sua realização.

11) Diferenças entre os atos em que o verbo ilocucionário correspondente tem um uso performativo e aqueles em que isso não acontece.

12) Diferenças quanto ao estilo de realização do ato ilocucionário.

A primeira diferença se centra na questão do propósito que, nos termos da ação linguística posto pelo escopo pragmático, é "uma tentativa de levar o ouvinte a fazer algo. O propósito de uma descrição é ser uma representação (verdadeira ou falsa, precisa ou imprecisa) de como alguma coisa é. O propósito de uma promessa é assumir o falante a obrigação de fazer algo" (SEARLE, 2002, p. 3-4). Ou seja, dentro do escopo das diferenças, é o principal ponto de macrodefinição de classificação da performatividade de um ato linguístico. 
Já a segunda diferença se concentra em como a performatividade de um ato de fala age na relação linguagem-mundo, mais especificamente na chamada direção do ajuste. "Algumas elocuções têm, como parte de seu propósito ilocucionário, fazer as palavras (mais precisamente, seu conteúdo proposicional) corresponder ao mundo; outras, fazer o mundo corresponder às palavras. As asserções estão na primeira categoria, as promessas e os pedidos, na segunda" (SEARLE, 2002, p. 4-5).

Por sua vez, a terceira diferença é a chamada condição de sinceridade do ato, ou seja, a condição psicológica de quem realiza o ato de fala. Searle $(2002$, p. 8) as classifica, basicamente, em três tipos, representados por letras maiúsculas: "B para believe (acreditar), W para want (querer), I para intend (ter a intenção, intentar)".

A condição de sinceridade - junto com o propósito ilocucionário e a direção do ajuste - são as três dimensões cruciais para a taxonomia de Searle. Afinal, no limite, o propósito diferencia, o ajuste coloca na realidade - realidade aqui vista como a interação entre linguagem e mundo tal como bem nos inspira Wittgenstein - e as condições de sinceridade avaliam determinado ato de fala.

A quarta diferença se concentra na questão da ênfase. A ênfase se concentra na gradação da própria performatividade dentro de um determinado ato. "Sugerir" e "insistir", por exemplo, podem ter o mesmo propósito ilocucionário, como bem descreve Searle, mas um comprometimento diferente. É o mesmo caso entre "pedir" e "suplicar", cuja própria imagem mental do ato implica performances diferentes (aqui podemos até pensar na distinção não só linguística, mas também física entre atos diferentes).

Já a quinta diferença se refere à posicionalidade do emissor. Na letra searliana, isso é bem definido pela distinção que "um general convida (ordena) um soldado a fazer algo" e "um soldado convida (sugere) um soldado a fazer algo". Aqui entram não só questões de hierarquia, mas também de legitimidade social. Ela é diretamente relacionada com a décima diferença.

A sexta diferença é em relação ao interesse. Há aqui uma combinação binária entre falante e ouvinte: falamos coisas que são de interesse de ambos, de interesse de apenas um (só do falante ou só do ouvinte) ou mesmo que é do desinteresse de ambos. Apesar de Searle exemplificar a distinção com o par opositivo congratulação-condolência, a sexta diferença é bem mais múltipla do que isso, indicando dissimulações, hipocrisias e outros interesses que, normalmente, são muito presentes em atividades comunicacionais. 
Por sua vez, a sétima diferença possui interesse no contexto circundante no ato de fala. Seu foco está nas ações linguísticas representadas por "expressões [que] servem para relacionar emissões com outras emissões e com o contexto circundante", tal como uma objeção (SEARLE, 2002, p. 9).

A oitava diferença se centra na temporalidade do ato de fala. Temporalidade essa expressa tanto pela construção frasal (i.e. tempo verbal) como pelo conteúdo proposicional.

Já a nona diferença é acerca da necessidade de determinada ação linguística. Por exemplo, para pedir um prato de comida em um restaurante, você precisa pedi-lo ao garçom (ato necessário). No entanto, para separar camisas azuis de vermelhas, você não precisa enunciar "Essa é uma camisa azul" para separá-la, basta fazê-lo fisicamente (ato não necessário).

A décima diferença é aquela que, tal como o próprio Searle (2002, p. 10) admite, "Austin fala algumas vezes como se julgasse que todos os atos ilocucionários são dessa espécie". Ou seja, estamos falando da institucionalização extralinguística: certos atos de fala só podem ser ditos pelas pessoas que possuem autoridade para isso. É o famoso caso: só pode dizer "Eu nomeio esse barco como Queen Elizabeth" quem tem a autoridade para isso. Searle, ao mesmo tempo em que relativiza essa ideia austiniana, acaba expandindo o conceito em uma direção interessante:

Para que eu enuncie que está chovendo ou prometa vir vê-lo, só preciso obedecer às regras da linguagem. Nenhuma instituição extralinguística é necessária. Essa característica de certos atos de fala, a de requerer instituições extralinguísticas, deve ser distinguida da característica 5, a de que certos atos ilocucionários exigem que o falante, e possivelmente também o ouvinte, tenha um certo estatuto. As instituições extralinguísticas frequentemente conferem estatuto de uma maneira relevante para a força ilocucionária, mas nem todas as diferenças de estatuto derivam de instituições. Assim, um assaltante armado, por possuir um revólver, pode ordenar a suas vítimas - em oposição a pedir, rogar ou implorar que levantem as mãos. Seu estatuto, porém, não deriva de uma posição numa instituição, mas da posse de uma arma (SEARLE, 2002, p. 10-11).

Searle, intencionalmente ou não, expande o conceito de instituição extralinguística para a ideia de competência, apenas implícita na quinta diferença (posicionalidade). Competência essa que, curiosamente, faz Austin ganhar respaldo em sua generalização. Afinal, só pode 
enunciar que está chovendo quem possui competência para isso (ou está na chuva ou está contando uma história chuvosa), o mesmo caso para as promessas.

No limite, a competência é acerca da capacidade do emissor de cumprir as condições de êxito de um ato ilocucionário, ponto central para a letra austiniana. Tal como bem afirma Austin (1975, p. 116), "a não ser que certo efeito seja obtido, o ato ilocucionário não será realizado de forma feliz, com sucesso. Isso não é dizer que o ato ilocucionário é conseguir certo efeito. Não se pode dizer que avisei uma audiência a não ser que ela escute o que eu disse e tome o que eu digo em determinado sentido".

A 11a diferença se centra na função verbal dentro de um ato linguístico, ou seja, se o indicador de ação (i.e. o verbo) centra a capacidade performativa em si ou não. Exemplo: concluir possui essa capacidade (só podemos concluir algo ao enunciá-lo), mas gabar não (você não se gaba ao dizer "eu me gabo").

Por fim, a 12a segunda diferença é uma questão de estilo. Aqui, o ato de fala fica vinculado a condições como gírias (enunciar um determinado verbo e enunciar um similar composto por um palavrão possuem estilos diferentes, sendo atos de fala distintos), aspectos culturais e, até mesmo, características sonoras da fala como o sotaque.

Assim, podemos definir esse conjunto de diferenças pelas suas palavras-chave: propósito ilocucionário, direção do ajuste, condição de sinceridade, ênfase, posicionalidade, interesse, contexto circundante, temporalidade, necessidade, institucionalização extralinguística (competência), função verbal e estilo. E é por meio dessas palavras-chaves que esquematizaremos a pragmática do jornalismo de internet.

O propósito ilocucionário do jornalismo de internet é o exercício do jornalismo utilizando a linguagem hipertextual. O labor jornalístico se adapta às condições que a web permite, focando mais nas questões de uma interação e virtualização humanas. Aqui, as notícias não são feitas para os olhos da leitura silenciosa como em um jornal, mas sim para uma imersão plena.

Com isso, há o desenvolvimento da hipermídia com os seus newsgames, infográficos interativos, webcasts. Além disso, há uma simulação clara do "tempo real": a fluidez das postagens na internet mostram o hic et nunc das notícias do mundo.

Já a direção do ajuste, especialmente por causa da ideologia jornalística, é fazer as palavras corresponderem ao mundo, tal como mostramos anteriormente através do asserverar do jornalismo. Esse é um dos principais pontos da visão dos jornalistas acerca do seu ato de fala. 
A condição de sinceridade é a do I (intend) e está diretamente vinculada com o asserverar que indica a direção de ajuste. Prática linguística permeada por um imaginário deontológico, o jornalismo se calca no asserverar enquanto missão e atribui o não asserverar àqueles que fazem "mau" jornalismo.

A ênfase, normalmente, é aquela que demonstraria legitimidade e autoridade no assunto. Se um site qualquer pode abusar esteticamente, os hipertextos vinculados aos profissionais da notícia buscam a simplicidade e a funcionalidade para passar as informações. A única exigência é a clareza de articulação para melhor compreensão.

A posicionalidade é de plena legitimação do jornalista pela sociedade (ou, pelo menos, legitimação que o jornalista acredita que a sociedade the direciona). Tal como qualquer jornalista, agem na ideologia do "Quarto Poder", do watchdog da sociedade.

Talvez a melhor frase exemplificadora de tal posicionalidade venha da ficção e não da teoria. $O$ editor Dutton Peabody (interpretado por Edmond O'Brian), do filme $O$ Homem que matou o Facínora (The Man who shot Liberty Valance, de 1962), afirmava: "Sou um jornalista! Não sou um político. Os políticos são o meu alimento. Construo-os; derrubo-os. Mas nunca seria um. Não poderia ser um - isso distrair-me-ia. Sou a vossa consciência. Sou uma pequena voz que atroa na noite. Sou o vosso cão de guarda que uiva aos lobos" (apud TRAQUINA, 2005, p. 130).

Já o interesse é uma das questões mais problemáticas representada por algo que podemos denominar "paradoxo do jornalismo": o interesse do jornalismo é pelo interesse público ou pelo interesse do público, pelo que a "sociedade" deve saber ou pelo que as pessoas querem saber.

Aqui são famosas duas frases. A primeira é de George Orwell, que diz que o jornalismo publica aquilo que as pessoas não querem saber ou dizer. Eis aqui o interesse público. Já a segunda é de Evandro Carlos de Andrade quando foi diretor de jornalismo da Rede Globo:

É claro que o telejornal tem que atender ao "interesse público", isto nem se discute; mas o "interesse do público" também precisa ser satisfeito. Em jornalismo, $90 \%$ do que se divulga só serve para conversa durante o jantar, não modifica a vida das pessoas em nada. A vida é modificada por uns tantos atos do governo, que definem a cobrança de mais impostos, a proibição disso ou daquilo, o aumento de preços, a alteração dos salários e dos direitos. Mas o "interesse do público" também é fundamental, para que as pessoas tenham o que conversar. Já imaginaram chegar a um jantar e 
perguntarem se você leu o artigo 3으 da lei no 5.432? Seria insuportável um jantar movido a leitura de legislação (JORNAL..., 2004, p. 288-289).

Deixando esse debate deontológico paradoxal de lado, a questão aqui é que, tecnicamente, o jornalismo de internet, por sua derivação do jornalismo, é de duplo interesse. No entanto, é interessante observar que isso só ocorre em condições ideais, deontologicamente prescritas. Talvez, boa parte das notícias seja só de interesse dos jornalistas, sendo apenas ideologizada enquanto interesse público.

Já o contexto circundante pode variar de acordo com o objeto. Normalmente, é sempre de afirmação e conclusão, mas pode adquirir status de negação, objeção ou questionamento se for considerado uma crítica jornalística.

A temporalidade, deontologicamente, é do presente. No entanto, pode haver usos do passado e, na prestação de serviços, uso do futuro. Além disso, há um jogo da temporalidade do "tempo real" como se a internet estivesse "em cima do acontecimento" sem a questão de uma grade de programação, tal como a do rádio e a da TV, tornando-se mais maleável para lidar com notícias urgentes.

Por sua vez, a necessidade é vista enquanto crucial. Há uma constante necessidade de notícias nas diversas plataformas digitais da web. Mesmo quando está no formato de feed ou meme, o conteúdo jornalístico precisa de um ato de fala jornalístico para se realizar dentro de seu discurso.

A institucionalização extralinguística é um dos elementos mais comuns em qualquer tipo de jornalismo. E aqui não se resume aos portais e sua personificação jornalística sob alcunha da "Redação". O jornalista, através do seu nome, é uma institucionalização extralinguística e nisso se reside muitos blogs e páginas de rede social. Afinal, quem dá essa notícia não é qualquer um, mas o jornalista $X$. No webcasting, basta ver o caso da Mídia NINJA e seu protagonismo nos protestos de rua brasileiros na metade de 2013.

De maneira similar à necessidade, a função verbal é um ponto deontológico do jornalismo. A notícia só se realiza quando há um ato de fala digital jornalístico.

Por fim, o estilo é o campo de maior mutação, mas sempre calcado em um culto à simplicidade. Esse estilo, para muitos, é o índice da credibilidade. No entanto, surgem formas mais elaboradas, tal como o storytelling. 
Basicamente, o storytelling no jornalismo de internet visa a quebrar o primado da pirâmide invertida e colocar as notícias em uma teia narrativa, buscando maior imersão do internauta com os fatos. Com isso, constrói-se um aparato que consegue dar vida nova a práticas jornalísticas experimentais como o jornalismo literário e o jornalismo gonzo. Tudo isso, buscando não só representar a experiência dos fatos, mas também convergindo em plataformas. Afinal, porque se escrever sobre algo, se também podemos colocar um clipe audiovisual sobre ele?

Nesse mundo de convergência, o fluxo de produção do jornalista de internet se pluraliza e se torna mais rápido, mas continua sendo o mesmo. No entanto, isso não é uma exclusividade dessa modalidade informacional. Como dissemos, o mundo atual é ciber. Qualquer jornalista, dessa maneira, sofre com essa aceleração do fluxo de produção e recai com novos processos de apuração (que resultam, muitas vezes, em menor contato físico e mais contato virtual com fontes e fatos) e maior fluxo de pautas abordadas. O mundo é ciber e o próprio jornalismo se virtualiza, tomando cuidado para não cair no mau exercício da produção, transformando a apuração em mera checagem factual ou retransmissão de notícias feitas por um determinado veículo (ou seja, hipertrofiando a agenda). E com o webcasting, tais preocupações só se intensificam.

\section{Referências}

ARMENGAUD, F. A Pragmática. São Paulo: Parábola, 2006.

AUSTIN, J. L. How to do things with words. Cambridge: HUP, 1975.

BECKER, B.; MATEUS, L. Repensando o ensino do Jornalismo Audiovisual: o potencial das webtvs universitárias. In: ENCONTRO NACIONAL DE PESQUISADORES EM JORNALISMO, 9., Rio de Janeiro, 2011. Anais... Rio de Janeiro: SBPJor-UFRJ, 2011. Disponível em: <http://sbpjor.kamotini.kinghost.net/sbpjor/admjor/arquivos/9encontro/CC_30.pdf>. Acesso em: 8 dez. 2013.

JORNAL Nacional: a notícia faz história. Rio de Janeiro: Jorge Zahar, 2004. (Memória Globo).

LACALLE, C. As novas narrativas da fiç̧ão televisiva e a Internet. Matrizes, v 3, n. 2, p. 79-102, jan./jul. 2010.

MONTAGUE, R. Pragmatics and intensional logic. Dialectica, v. 24, n. 4, 277-302, Dec. 1970. 
NOGUEIRA, L. O jornalismo audiovisual on-line e suas fases na web. In: CONGRESO IBEROAMERICANO DE PERIODISMO EN INTERNET, 5., Salvador, 2004. Anais... Salvador: AIAPI-UFBA, 2004. Disponível em: <http://s3.amazonaws.com/lcp/ciberperiodismo/myfiles/AIAPI\%202004\%20Leila\%20Nogueira.pdf>. Acesso em: $8 \mathrm{dez}$ 2013.

RAJAGOPALAN, K. Nova pragmática. São Paulo: Parábola, 2010.

SEARLE, J. R. Speech acts. Cambridge: CUP, 1976.

SEARLE, J. R. Expressão e significado. São Paulo: Martins Fontes, 2002.

SEARLE, J. R.; VANDERVEKEN, D. Foundations of illocutionary logic. Cambridge: CUP, 2009.

TRAQUINA, N. Teorias do Jornalismo. 2. ed. Florianópolis: Insular, 2005. v. 1.

Recebido: $14 / 08 / 2013$

Aprovado: 09/09/2013 Approved: 09/09/2013 